\title{
The Educational Aspect of School Libraries’ Design and the Students' Territorial Behavior
}

\author{
Dr. Snunith SHOHAM, Chair, Department of Information Science, \\ Bar-Ilan University, Israel \\ Dr. Zehava SHEMER-SHALMAN, Head, Librarianship \& Information Science \\ Department, \\ Oranim Academic College of Education, Tivon, Israel
}

\begin{abstract}
In a study combining qualitative (observation and interviews) and quantitative (questionnaires) methods, the researchers examined the territorial behavior of students and the implications of the internal arrangement of the library space for the students. The territorial behavior observed in the libraries could be seen in where the students decided to sit and how they used library furniture (including chairs, armchairs, computers and the librarian station). Most of the students preferred sitting in a central area in the library. However, for the most part, students chose to sit in places that enabled them to maintain territorial control. While many students sat in groups for both social and study purposes, some of them (particularly the older students) had a need to protect against intrusion into their personal space. This was achieved by sitting at the tables with their backs to the entrance, by body language and, at times, even by using personal belongings to demarcate personal territory. Library planners and librarians must be aware of these "conflicting" needs in order to adapt the design to the behaviors typical of the groups that use the library.
\end{abstract}

\section{Introduction}

Research in environmental psychology shows the connection between buildings, places of residence, seating areas and additional spaces and behavior. People behave differently in different settings and under different conditions. Human behavior can be changed through different planning of space or by repositioning furniture within a given space (Sommer, 1968; 1970). Proshansky (1976) states that conditions of noise, furniture, light and proximity to other people affect feelings of tension and behavioral responses.

The issue of territoriality was studied by Sommer $(1967,1968)$ in the context of academic libraries, Shoham (1991) in the context of public libraries, and the research presented here focuses on school library spaces.

The library is a separate territory within the school, in which students and librarians act. Various pieces of furniture and equipment, and their arrangement and position affect the behavior of students in the library. The purpose of this study was to examine the territorial behavior of students and the implications of the internal arrangement of the library space for the students. 
The study examined the behavior of students in the library relative to the tables in the study areas, the position and design of the librarian station, armchair area and computer stations, and how this impacts on the educational situation. The target group in this study was students between the ages of 12-18 who attend high schools in Israel.

\section{Literature Review}

The school library is a study space, and the behavior of students while in the library is influenced by several factors, including their individual learning styles, the physical conditions in the library, their personal need for privacy and territorial behavior. Different age groups have been shown to have different needs and behavior.

\section{Design of Study Space}

Examination of the study conditions in school libraries and the work conditions of the librarians shows a relationship between people and the environment and furniture surrounding them, including computers and multimedia devices. Research on study habits in various types of classrooms indicates a connection between the design of the room and learning. These changes are not only the result of differences in study habits, but also of architectural or engineering developments. As early as the 1970s, educators began to understand that physical conditions have an impact on how students relate to the classroom, their studies and to school in general and that this is also manifested in their behavior. This opinion was influenced by educational movements promoting open education classrooms and open space schools. Both of these educational movements developed new approaches to the use of classroom space (Weinstein, 1979). The findings of research into the open space method and open education classroom allow for comparisons between classroom and library conditions. Open education classrooms are particularly similar to libraries (Walberg \& Thomas).

By monitoring activities in the classroom space, it was found that students prefer certain areas over others. Activity centered in some areas of the classroom, and there were no concentrations of students in other areas. The explanation given for this difference relates to the spaces allocated for the activities. Activities for which large spaces were allocated attracted more students than activities done in small spaces. Students preferred studying in areas that allowed them to study with as many other students as possible (Shure, 1963).

Changes in the internal organization of a classroom also lead to changes in the behavior of the students and of those supervising them. The study, based on this theory, determines that a relationship exists between the environment and environmental design and human behavior. It was found that physical changes to classroom space caused teachers to behave differently. They became less pleasant when they were unable to control the students, the students showed less interest and conflicts between students arose (Weinstein, 1977). Teachers noted a link between where students sit in the classroom and how well they learn. Students who sat at the front of the classroom and closer to the teacher showed more progress, generally had a high level of self-esteem and had higher achievements. Those who sat in the back were generally students with high social needs occasionally had negative attitudes towards school and sometimes had low self-esteem (e.g. Walberg, 1969; Becker, Sommer, Bee \& Oxley 1973; Morrison \& Thomas, 1975).

The spaces between people and the sense of privacy have a significant effect on learning conditions in the library. Privacy here means a lack of interference from 
neighbors, the ability to isolate oneself, intimacy and anonymity. Studies that examined privacy conditions in educational settings found that students in open classrooms noted that when a large space is broken into subsections, they have a greater sense of "privacy". In a study conducted by Brunetti (1972), over half of the respondents indicated that they could find private areas in open classrooms with 'dividers' such as furniture in the general space. In contrast, only about one fourth of the students in regular classrooms, where students are concentrated in a single space noted that they felt 'privacy' in their classrooms.

\section{Territoriality}

Similar to the classroom, the library is a territory that offers different learning and work conditions, which require thought and planning. A process of structural planning requires three elements to be taken into consideration: the aesthetic, the functional, and the behavioral (Cohen \& Cohen, 1979). The behavioral dimension has received the least attention. Human behavior can be altered by planning spaces differently or locating furniture differently within the given space (Sommer, 1968).

Most researchers in the behavioral sciences agree that the term "territory" is relevant in describing and explaining human behavior. This term entered the human behavioral sciences from the biological sciences. It particularly pertained to claims of ownership over a geographic space, the marking of the space, and its defense against others when necessary (Brower, 1965). Sebba (1981) defines “territorial behavior" as a pattern of social-spatial behavior that is manifested in how organisms use their living space. This territorial behavior is ascribed on the one hand to the need for human proximity to achieve a common goal (such as security or fulfilling desires) and, on the other hand, to competition over the physical environment and resources.

Lyman and Scott (1967) distinguish between four types of territories in human societies: (1) public territories, such as parks, which give the citizen freedom of access, but not necessarily of action; (2) home territories, which are public areas taken over by groups or individuals, such as children's clubhouses or cafés that cater to habitués; (3) interactional territories, areas where social gatherings may occur; and (4) body territories, i.e., personal spaces, which are the most private and inviolate spaces belonging to the individual.

Altman (1975) suggests that personal space and territorial behavior are mechanisms used to achieve a desired level of privacy and defines privacy as selective control of access to the self or to one's group. Proshonsky and Rivlin (1967) assert that this behavior involves a person's attempt to gain control over a certain piece of space. The operative significance of "territorial behavior" refers to "ownership" and the use of accessories within the territory, such as tables, closets, chairs, and so on (Altman \& Haytorn, 1967).

According to Hall (1966), the anthropologist, the way people use space affects their ability to relate to other people and to sense whether they are near or distant from them. He coined the concept of "proxemics". Ardrey (1966) adds that in all human societies people have a drive to hold a certain territory that surrounds them, a private territory, and to defend it against invasion; however, the size of the territorial space can vary from culture to culture. Territoriality consists of personal space, privacy and personal boundaries.

Goffman (1969) noted the importance in public territories of the form of demarcation. Molcho (1998) explained that setting out equipment on a worktable is an 
act of demarcating territory and gave examples of human behavior that express control, such as when people, immediately upon entering a hotel room, disperse objects around the room and thereby demarcate the new territory, or when children scatter toys through the rooms of a house or family members disperse articles of clothing.

The library is by nature a public territory, and it is divided into areas at different levels of commonality such as the librarians' desk, librarians' station, tables for work, carrels for individual work and computers. In a school library, the two kinds of "territory holders" relate differently to territory: the librarians regard their workplace as a "semi-private" and establish territory where they spend many hours of the day, whereas the students see the space as being at their disposal so long as they are in it. The choice of location when sitting at a table also has a territorial significance. Choice of seating location sometimes manifests a strategic choice in regard to other people and can also be an effective means of cooperating with them. There are differences between modes of sitting at the dining table in a private home, restaurant, office, library or at the bar in a pub.

Pease (1981) specifies four basic sitting positions a person can take: (1) sitting beside a person on the same side of the table, expressing and enabling full cooperation; (2) sitting beside a person at the corner of a table, enabling eye contact, proximity and friendliness; (3) sitting straight across the table with the table separating the people, with each having a separate space, and sometimes with objects serving as territorial boundaries; and (4) sitting diagonally across a table, expressing each person's territorial independence.

The shape of the table influences the relations between the people sitting at it. A round table is less formal and has no explicit place for an authority or power figure. A rectangular table, however, enables a strategic location vis-à-vis others. Pease (1981) notes that sitting at a table with one's back toward the wall or toward a solid piece of furniture lends people security and strategic control that they would not have if they sat with their back toward the entrance or toward an open space, causing them to feel cut off from whatever is happening behind their back.

In studies conducted in academic libraries, a marked tendency was found to sit alone and choose the farther tables (Sommer, 1967; Fishman and Walitt, 1972). Cohen and Cohen (1979) found that people prefer to sit alone in the library in isolated locations, with their back and side shielded, so as to maintain the level of privacy they need. In a study conducted in reading rooms of public libraries, it was found that $65 \%$ of the subjects chose tables located in corners in the library periphery; only 35\% of the users sat at more central, exposed tables (Shoham, 1991).

\section{Methodology}

Both qualitative and quantitative research methods were used. The qualitative phase included observing four high school libraries in Israel (1,222 students were observed), photographing of situations in the libraries, and open ethnographic interviews with all of the librarians and with five students in each library.

To map behavior in the various areas of the library, three one-day observation sessions at four schools were held (a total of 12 full days of observation). In each observation session, the observer used a diagram of the library (prepared after early observations of the library), to mark where students chose to sit or gather. Each student entering the library was assigned a number and recorded on the diagram. This record 
was maintained throughout the entire observation session, providing a picture of the concentration of students in the library during the various hours of operation. The different seating areas were photographed, and the pictures were analyzed at a later date.

In addition to observation sessions, interviews were conducted with eight librarians and 20 students. The interviews all had a similar structure and were conducted freely. The conversations were recorded, transcribed and then analyzed.

After completion of the qualitative phase of the study, questionnaires were distributed to 394 students in these libraries.

\section{Findings}

The observation sessions, questionnaires and interviews provided the researchers with insight into where students sit in the reading room, near the armchairs and near computers, and identified the areas where students concentrated in the space and how they behave near the librarians' station. The map showing concentration of students showed that $53 \%$ of them elected to sit at the tables; $17 \%$ sat in the armchair areas and $11 \%$ remained in the area of the librarian station. Seven percent went directly to the photocopiers and another $7 \%$ to the computer workstations.

Students were also observed standing for a lengthy period, and they sometimes sat in between the bookshelves and read books there (5\% of those observed) (see Figure $1)$.

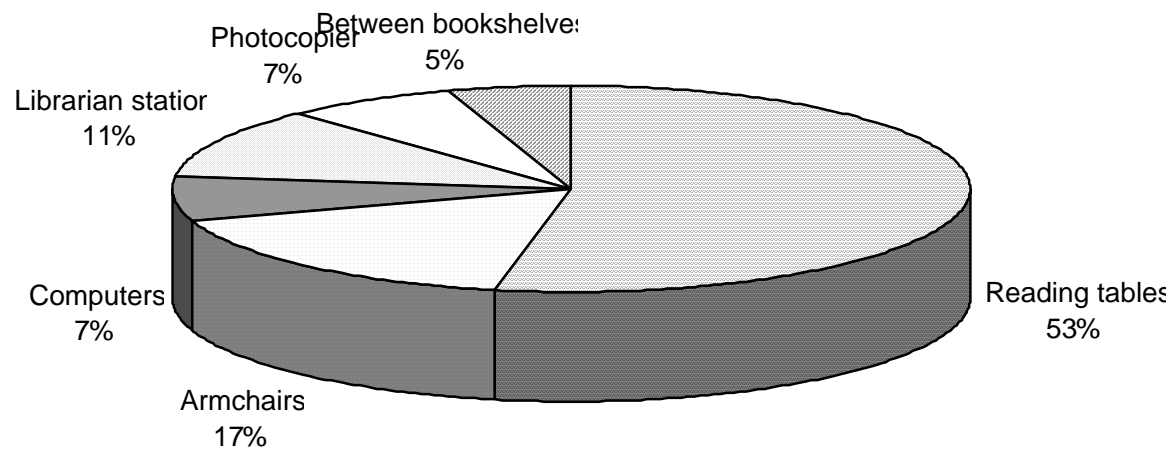

Figure 1. Distribution of students in the library

This distribution in the library space matched the declared purpose of their visit to the library: Close to two-thirds came to study, and one third of questionnaire respondents reported that they came to the library for social reasons.

\section{Seating in Study Areas}

In monitoring those who spent time in the reading room in the areas allotted for sitting at tables, three categories of seating locations were defined: 
1. Sitting at a central table. This refers to a table surrounded on both sides by other tables, a table near the librarians' station, or a table close to the main aisle.

2. Sitting in the corners of the room and in the periphery of the reading area. This includes sitting at a table that is located behind furniture, such as separate bookcases, that creates a partition and divides the main space into subspaces, or sitting at tables that are not surrounded by other tables.

3. Sitting in carrels.

These seating conditions existed in all four of the schools, except that Schools 1 and 2 did not have carrels.

In the observations, special attention was paid to the first 15 students who entered the library in the morning and chose a seating location in the reading area. The choices these students made were not influenced by the fact that seating locations they sought had already been taken by students who came to the library earlier. Furthermore, the researchers record the total number of individuals who entered the library throughout the observation periods.

Figure 2 presents the breakdown of the seating locations among the 170 students who first entered the library. Close to two-thirds (62\%) of them chose to sit in a central location exposed to "neighbors" and "passersby," and about one-third (35\%) chose tables in the corners of the library.

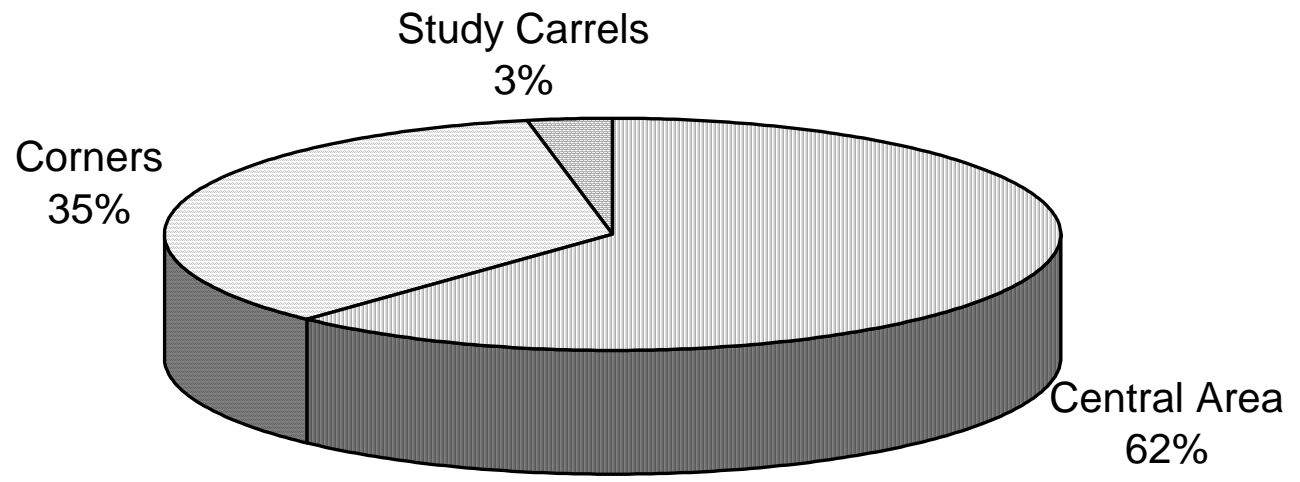

Figure 2: Breakdown of students entering library first (according to observations) $(N=170)$

Only $6 \%$ of the 90 who were the first to enter Libraries 3 and 4 , the only libraries to have carrels, chose to sit in carrels. These findings are similar to the findings regarding all of the students observed throughout the entire three days of observations: $61 \%$ of the 671 students who were observed spending time in the reading area sat in central locations of the room, and 38\% sat in corners of the room. About one-third (32\%) of the students who sat in central areas sat in very high traffic areas in the library and near the librarians' station. The findings of the questionnaires also confirmed the preference for sitting in central areas. Interviews with librarians further strengthen these findings. Librarians noted that when students entered the library sporadically, different 
students selected where to sit differently: sitting near friends, sitting in a more isolated area at a peripheral table or in a carrel, sitting near a relevant collection of books or sitting in a particular location to be near equipment or devices in that area such as air conditioners or computers.

Sitting near friends: Some students chose to sit in central areas and to sit together. "They like to be together. They come for this 'togetherness'. They are concentrated in one area and work together, simply a big group." This is how the librarian from School 2 described it and emphasized that the most popular tables are actually those that are close to the librarians' station, where there is a great deal of traffic. Another librarian noted that in areas where the tables are only large enough for four students, students move chairs to the corners of the table and manage to have six sit around the table.

A student at School 4 explained, "Sometimes I like to look around and see who's here, to see if a friend has come and can help me and we can study together."

Sitting near a relevant collection of books: Some of the librarians noted that students wanted to sit near the collection of books they needed for their studies. The librarian at School 1 said that the junior high students "like to sit near the reference section, especially near the encyclopedias. Those are their important reference materials." At School 3, many students were observed standing with volumes of the encyclopedia near the librarians' station, looking through them or reading them while standing or sitting on the floor between the bookshelves as there are no tables near these shelves.

Quiet areas: It emerged from the observations that the quiet corners of the library were not particularly popular, even though $41.9 \%$ of the students who answered the question "Why did you choose to sit in the place where you are now sitting in the library?” answered, “A quiet place.” However, a comparison of these responses to their observed behavior revealed incompatibility. Sixty-one percent of the students sat in central locations of the library, especially main aisles and high traffic areas.

According to the librarian, young students (grades 7-10) and older students (grades 11-12) have different needs and preferences when it comes to quiet areas. "The older students complain. They claim they can't study because of the noise.” Some older students turn the comfortable and quiet place to their regular place, even if there is no noise. The younger students, in contrast, choose the noisier parts of the library, such as near the librarian

Study Carrels: Not all of the schools observed had study carrels. Among the questionnaire respondents at Schools 3 and 4 (where such carrels exist), only a few students marked on the diagrams that they sat in the carrels. The librarians noted that they are not attractive place and that very few students chose to sit at the carrels. They further noted that most of the students like to be in the large spaces in the library. Another reason given by a student at School 4: "I tried once, but couldn't work there. It was too boxed in. I didn't feel comfortable there, because I need the space.”

Reasons for preferring certain seating areas: Analysis of the questionnaires shows that the most common reasons for selecting a seating area is a quiet place, comfort and sitting near friends (see Figure 3). The percentage of students who chose to sit in a quiet location and came to the library alone (52.2\%) or with one friend (51.1\%) was significantly higher than the percentage of students who came with a group of friends $28.2 \%$ ) and, in contrast, the percentage of students who chose to sit far away 
from others was higher when they came alone (13\%) compared to $5.1 \%$ of those who came in groups $(\mathrm{N}=394)$.

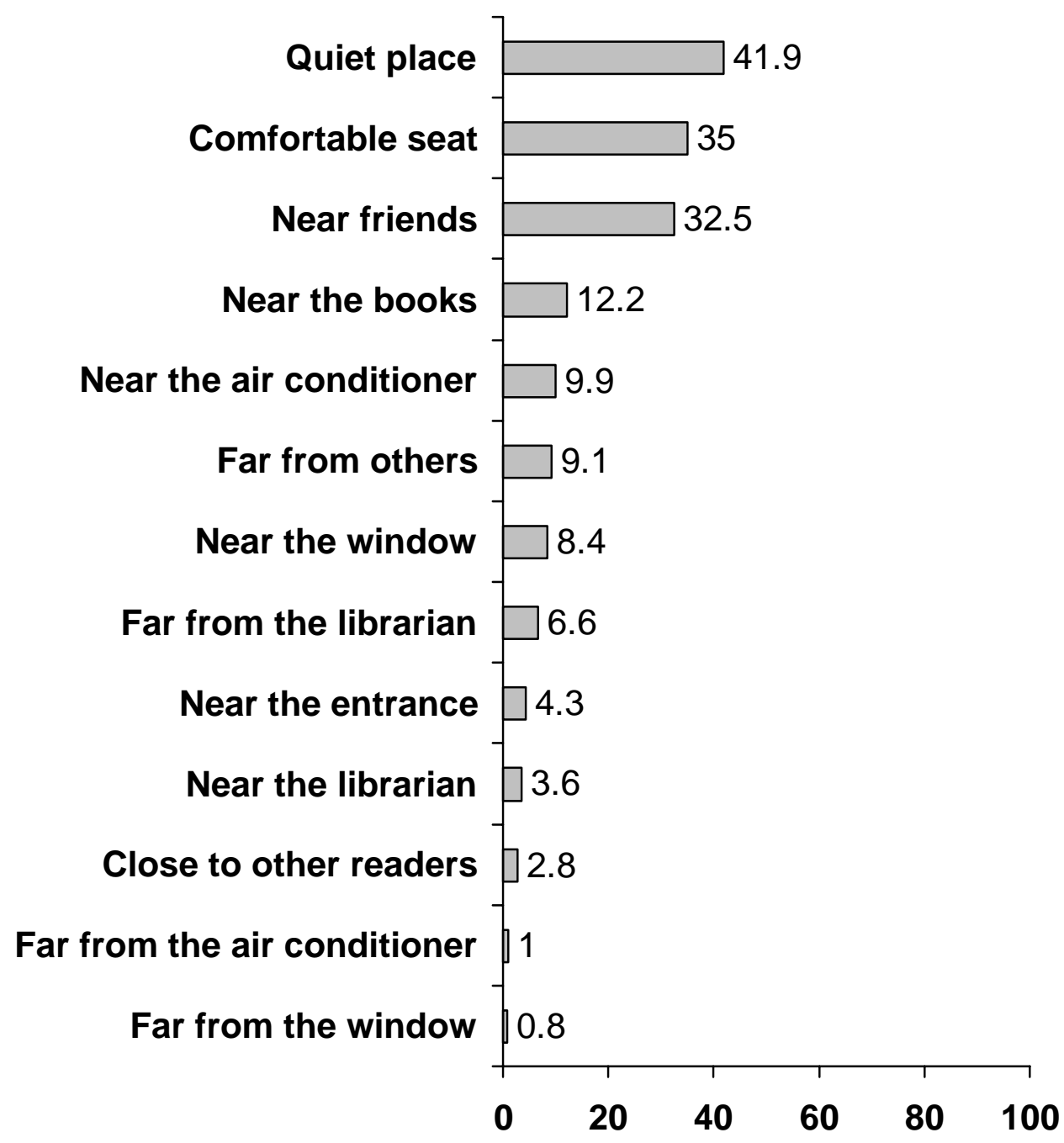

Figure 3: Breakdown of Reasons for Selecting Place to Sit at the Library (Percentage) $(N=394)$

No significant differences were found due to social reasons for coming to the library and selection of seating near the window or far from the window, near the air conditioner, the entrance or the selection of a comfortable place.

\section{Sitting in Armchair Areas}

All four libraries had armchair areas, where seating was informal. Seating here was designed for relaxation and comfort. The students in this area generally sat in groups or in pairs. The conversations and discussions the students had while sitting in the armchair area were sometimes loud, creating a club-like atmosphere. There was no study or writing activity there. The researchers sometimes observed couples sitting close together in this area, cuddling and hugging. 
Reading activity in this area involved materials taken from the magazine racks nearby or daily newspapers. Students did not remain in this area for long. They sometimes came into the library and stayed in the armchair area for a short time, only then moving to one of the tables in the study areas and beginning to study, read and write. The armchair area was used as a meeting place: students entered the library, sat in an armchair and waited without reading or performing any other activity, and when a friend arrived (for whom they had been waiting), they left the library together. Sometimes, when a large group entered the library and went to the armchair area, students moved chairs from a nearby table and closed the area off into a square.

The informal seating in the armchairs was frequently quite crowded, with three students even sitting in two chairs, and not because there were not enough chairs. Students were also observed stretching out across several chairs.

When the armchair area was empty, students preferred to sit on the chairs against the wall, so that that they were facing the entrance. The students interviewed explained that they sat there "in order to see who came in and to be able to call them over to join..." The interviewees gave the following reasons for selecting the armchair area: a place to spend spare time, comfort, an area that enables informal activity and serves as a meeting point for a large group of friends. These reasons were provided by both the students and the librarians.

The students explained their seating arrangements and special behavior in the armchair area by saying that the fact that the armchairs are arranged differently than the tables in the classroom turns the area into "an informal place" that does not have a study atmosphere, and it sometimes gives a "homey" feeling, explaining why they behave differently.

\section{Activity Near Computer Workstations}

Each of the four libraries had a different number of computers, and the computers were located in different areas of the libraries. In some, they were concentrated in a single area and in others, they were distributed.

Students were observed rushing over to this area even early in the morning, as soon as the library was opened. They entered the library quickly, sometimes even running over to the computer, as if they were trying to "save a seat". The first students to enter the library and went over to the computers, sat down and played alone. Sometimes a student entered with a friend, and the two sat down at a single computer. Sometimes students entered the library to find all of the computers in use. These students joined those who were already seated, by moving chairs from the study area near the computers. Students were also observed sitting at the tables near the computers and waiting until a space near a computer became free. Students spent a long time in front of the computers. The crowds that gathered there at times caused a commotion. The librarians described the crowds around the computers as being due to the small number of computers and the social needs of teenagers.

A connection was also found between computer use and the librarians on duty. When the librarian is not skilled in computer use, they do not turn the computers on. This may indicate that librarians have a need to control and monitor the computers.

\section{Activity Near the Librarians’ Station}


At the four libraries observed, librarians checked out books and offered assistance from the station. In all of the libraries, the librarians' workstations were located close to the main entrance to the library. All stations allowed librarians to observe those entering and exiting the library. In each school, the station was designed differently. In three of the schools, the station was the height of a table, and at one school the station was elevated. Due to the different physical conditions and planning, different behavior patterns were observed at each school.

Issues examined with respect to the station included control, privacy, closeness and convenience. (The data was gathered through observation and interviews.) The librarians used the word 'control' to refer to the issue of the location of their station and its influence on the behavior of the students. In all of the libraries, the station was located close to the entrance, making it difficult to 'cover' all of the library space. They claimed that they need to ensure conditions that also allow them to control the library's assets and the students leaving the library, as well as those within the library itself. "From this position, we can't control anything," said the librarian at School 4. To enable them to see, they arranged seating for themselves so that each librarian "always sees what's going on in her area. There's never a situation where the librarians don't see anything...There is no dead space."

With respect to the questions as to whether 'control' is necessary, the librarian responded that the type of activity in the library requires control. "When it's possible to control what's going on, the students behave properly, and when the station is far away, the presence of the librarian has no effect," meaning that in terms of student behavior, "they will try all kinds of things, even with food..."

The librarians want the station to be located in a place that enables them to control student behavior. They need to see and be seen. Placement of the reserved book collection near the station is an expression of 'control' in terms of protecting them.

When referring to the height of the station, the librarians related to the sense of privacy, peace of mind, proper working conditions, comfort and order. The librarian at School 4 noted that because their station is the height of a standard table, students lie down on it. She stated that this situation is an invasion of their privacy. Observations in School 4 showed invasions of the librarians' private territory. Students placed their belongings on the table and even on top of the librarians' belongings. They touched private belongings and writing implements. Students were also observed bending over the table to reach the drawers on the other side of the table.

In order to cope with the invasion of privacy, the librarians at School 4 found a partial and improvised solution by adding tables to the station. The addition of the table caused the students to be further away from the librarians in the high-traffic entrance area. It increased the area of the station and the personal territory of the librarians, strengthening the sense of privacy of the librarian sitting on that side of the station.

The need for privacy and defined personal territory led the librarian at School 3 to leave the station, which was designed as a separate unit in front of the workroom in the main aisle of the library and to move into the room itself. The room has windows, which allow the librarian to see what is going on in the library. The librarians at times left the station area and assisted the students in other areas in the library. This was the case when they needed to provide explanation near the bookshelves or to sit with a student and consult in a quiet area, far from large groups of students.

The librarian at School 2 stated that the fact that her station was elevated was a problem and prevented her from establishing a close and calm relationship with the 
students, because "it creates a distance from the students and disconnects me from the students. If I want to speak to a student in a different atmosphere, to generate closeness, I ask the student to come with me to a different area in the library, where this kind of 'monster' won't separate me from the student..."

In schools where the reserved books are behind the librarians' station, we observed a great deal of student traffic behind the station, meaning that this gave them legitimacy to invade the librarians’ defined territory.

\section{Territorial Behavior}

The territorial behaviors observed in the libraries were seen in the choice of seating location and use of library furniture. Students generally chose a seating location in the library that afforded them territorial control. Students who entered the library alone chose to sit where they could guarantee territorial control. Some wanted to have a commanding view of a large space and sat facing the entrance so that they could see those entering and leaving the library. This kind of behavior was observed at the reading room tables and in the armchair area, sometimes in expectation of a friend to study with or just for companionship. There were students who entered the library in a group and chose a seating location that allowed them to sit close together; they would put chairs together by moving them to the side of the table, and sit there adjacent to each other.

Sometimes two students entered the library together, but when they sat at the table they chose to sit diagonally across from each other at a distance. In doing so they guaranteed themselves defined personal spaces without any overlap between them.

Students who sat with their backs to the entrance wanted detachment from the environment and protection against invasion of their personal space. They cut themselves off from what was happening behind them, so that those entering the library could not identify them and disturb them. Their body language also expressed their desire to be separate. They put their hands over their ears and bent their bodies inward as if they had closed themselves off. Through their body language and using their personal items (e.g. bags or learning materials), students expressed the desire to guarantee themselves a territorial space. Students put their feet up on an adjacent armchair or sat by lounging across several chairs.

The penetration of a student's "territorial" area prompted reactions such as changing position, by turning their back to the intruder or laying their arm along the length of the table to mark a boundary. On some occasions there were also expressions of anger, or and students even left the table.

Choosing a seating location in a central area of the library, especially if it is close to the librarians' station, was particularly typical of junior high students. Also conspicuous was the marked tendency to increase territorial space by adjoining the adjacent table and placing items, mainly bags, on it. The tendency was observed when one or two students were sitting at the table.

At the librarians' stations, students did not respect the territorial needs of the librarians. When they came to the counter to receive service, the students would lean with their arms on the counter, bending over so that their upper body was pressing the table or even reclining on it. The students used the counter to leaf through the books they took out of the reference bookcase across from it, to sit, and sometimes even to stretch out. The counter became part of the general property, like any other table in the library. 


\section{Discussion and Conclusions}

The observations revealed a need to simultaneously defend territorial space and personal space; the students' need for proximity to others (friends and librarians) creates overlapping and, at the same time, tangential personal spheres that enable distance and detachment. These findings are in keeping with the findings of Goffman (1969), Molcho (1998) and Sommer (1968).

The territorial behavior observed in the libraries was expressed in the selection of where to sit and use of library furniture (including chairs, armchairs, computers and librarian station). Most of the students preferred sitting in a central area in the library and not at the far ends, a finding which is in contrast with the findings of research on users of public libraries. Furthermore, a high percentage of those entering the library came with one or more friends (about 75\%). The high percentage of those who come to the library with others explains the preferred choice of seating locations in central areas of the library.

For the most part, students chose to sit in places where they could maintain territorial control. Students, who came to the library on their own, sat where they could ensure territorial control and a view of a wide area. Similar observations were made in the armchair area. This control frequently enabled students to have friends join them later. Some students entered the library in a group and chose a seating location that allowed them to be in close proximity. They moved chairs and armchairs closer together to allow them to sit next to each other. Even in the computer area, we observed groups of students gathering around a single computer, even when other computers were available.

These findings are in line with known qualities of teenagers, including the need for the peer group, and this strengthens the opinion that libraries have conditions typical of an "open classroom”, and that students prefer to sit in central locations and in groups.

Students ensured themselves detachment from the environment and protection from intrusion into their personal space by sitting at the tables with their backs to the entrance. This was bolstered by body language that indicated the desire to detach. At times, students used their personal belongings to demarcate their personal territory. The need for territorial control and privacy, detachment from the surroundings, and protection against invasion of the personal space was different in the reading room than in the armchair area. In the latter area, more use was observed of body language (form of sitting, body position, use of hands and feet) for demarcating the territorial space, whereas in the reading area the student's personal space was demarcated by placing books and other items on the table or on an adjacent chair and sometimes also via the form of sitting.

Despite their need for personal space and territory, the students failed to respect the territorial needs of the librarians in all four libraries observed. They tended to lean against the counter with their arms and upper body, place their personal belongs on the counter and sometimes even sit on it (when the counter was low). The responses of the librarians to student behavior were varied. Some performed most of the service activities while standing up in order to cope with the student 'takeover' of the counter space. In one library, the librarian left the station and sat in his office. In another library they added additional tables in the corner to increase the personal space and achieve more distance between the librarian and the students.

Numerous students sat at tables near the librarians' station, despite its being a noisy area, because they required the assistance of librarians from time to time. This 
seems to conflict with the numerous responses received from students (42\%) that they prefer to sit in a quiet area. The term "quiet conditions" may be relative and personal, and not have a consistent definition among the students, on the one hand, and among the librarians, on the other. It should also be noted that "quiet" required for secondaryschool students (adolescents) is different from the conditions needed for other ages, and that the "young" junior high students need more help and therefore prefer to sit near the librarians more than the older students do.

In addition, the catalogs are located in the same area in the library, and there are students who need to be close to the librarian in order to bolster their personal feelings, as the librarian is an informal figure in the school system.

The study shows that it is important to factor the personal needs of library into educational considerations when planning a school library. Various learning styles, different physical conditions and territorial behavior are all expressed in behavioral terms in the education system, of which the library is a part.

The research shows professionals involved in school libraries and library designers the significance of design and planning of the physical conditions in the library on the behavior of users.

Planners of school libraries need to be aware of the territorial behavior of students and librarians. The different types of behavior related to different study styles, which can be seen in independent study or learning in groups, and in quiet or noisy conditions. It is important to recognize and understand the territorial behavior of users. Those who need well-defined territory will select a table that is not in the main area or a carrel, and others will prefer a position that gives them control over what is going on and allows them to sit close to their friends.

The study shows a need to divide the library into subspaces that provide solutions to various and often conflicting needs of students. Different students require different physical conditions to provide them with territorial comfort. These needs can be met through physical planning of the library. A clearly demarcated distinction between the more public and more private spaces can enable students with different needs to "find their place" in the library.

It is important to ensure that at least one-third of the seating areas enable independent and quiet study. The proportion is somewhat different when relating to junior high school students.

It is also important to plan solutions that answer the needs of librarians for control over what is going on and to prevent intrusions into their personal space.

This study's findings can assist in designing library space and furniture to suit the needs of both students and librarians.

\section{References}

Altman, I. (1975). The Environment and social behavior: Privacy, personal space, territory, crowding. Monterey, CA: Brooks \& Cole.

Altman, I., \& Haytorn, W. (1967). The ecology of isolated groups. Behavioral Science, 12, 169-182.

Ardrey, R. (c1966). The territorial imperative: A personal inquiry into the animal origins of property and nation. London: Collins.

Becker, F. D., Sommer, R., Bee, J., \& Oxley, B. (1973). College classroom ecology. 
Sociometry, 36 (4), 514-525.

Brower, S. N. (1965). The signs we learn to read. Landscape, 15 (1), 9-12.

Brunetti, F. A. (1972). Noise, distraction and privacy in conventional and open school environment. (Paper presented at the EDRA Conference). Los Angeles: University of California.

Cohen, A., \& Cohen E. (1979). Designing and space planning for libraries: A behavioral guide. New York: Bowker.

Fishman, D., \& Walitt, R. (1972). Seating and area preference in a college reserve room. College and Research Libraries, 33 (4), 284-297.

Goffman E. (1969). Behavior in public places. NewYork: The Free Press.

Hall, E. T. (1966). The hidden dimension. New York: Doubleday.

Lyman, S. M., \& Scott, M. B. (1967). Territoriality: A neglected sociological dimension. Social Problems, 15 (4), 236-249.

Molcho, S. (1998). Korpersprach. Munchen: Mosaik Verlag.

Pease, A. (1981). Body language. North Sydney: Camel Publishing.

Proshansky, H. M. (1976). Environmental psychology: A methodological orientation. In H. M. Proshansky, W. H. Ittlelson, \& L. G. Rivlin (Eds.), Environmental psychology: People and their physical settings ( $2^{\text {nd }}$ ed., pp. 59-69). New York: Holt, Rinehart \& Wilson.

Morrison, T. L., \& Thomas M. D. (1975). Self-esteem and classroom participation. Journal of Educational Research, 68 (10), 374-377.

Proshansky, H. M., \& Rivlin, L. G. (1967). Freedom of choice and behavior in physical settings. In H. M. Proshansky, W. H. Ittlelson, \& L. G. Rivlin (Eds.), Environmental psychology: Man and his physical setting (pp. 173-182). New York: Holt, Rinehart \& Winston.

Rivlin, L. G., \& Rothenberg, M., (1976). The use of space in open classrooms. In H. M. Proshansky, W. H., Ittelson,. \&L. G. Rivlin, . (Eds.), Environmental psychology: People and their physical settings. New York: Holt, Rinehart, \& Winston.

Sebba, R. (1981). The territorial division of the apartment as a factor influencing the residents' attitude towards it. (Doctoral dissertation, Technion - Israel Institute of Technology, Haifa). [Hebrew].

Shoham, S. (1991). The ecology of public library reference rooms. Public Library Quarterly, 11 (4), 43-51.

Shure, M. B. (1968). Psychological ecology of a nursery school. Child Development, 34 (3-4), 979-992.

Sommer, R. (1970). The ecology of study areas. Environmental \& Behavior, (December), 271-280.

Sommer, R. (1968). Reading areas in college libraries. Library Quarterly, 38 (3), 249260.

Sommer, R. (1967). Classroom ecology. Journal of Applied Behavioral Science, 3 (4), 483-503.

Walberg, H. (1969). Physical and psychological distance in the classroom. School Review, 77 (1), 64-70.

Walberg, H. \& Thomas S. C. (1972). Open education: An operational definition and validation in Great Britain and United States. American Educational Research Journal, 9 (2), 197-208. 
Weinstein, C. S. (1979). The physical environment of the school: A review of the research. Review of Educational Research, 49 (4), 577-610.

Weinstein, C. S. (1977). Modifying student behavior in an open classroom through changes in the physical design. American Educational Research Journal, 14 (3), 249-262.

\section{Author Note}

Snunith Shoham has a doctorate degree from the University of California, Berkeley, School of Library and Information Studies. She is Chair of the Department of Information Science, Bar Ilan University, Israel. She has published the books Organizational Adaptation by Public Libraries (Greenwood Press, 1984) and Classification and Browsing: The Conjunction of Readers and Documents (Sussex Academic Press, 2000) as well as many articles on School Librarianship, public libraries, knowledge organization, and Information gathering behavior. She is the Chair of the Israeli Council for Public Libraries.

Zehava Shemer-Shalman has a doctorate degree from the Bar Ilan University, Department of Information Science and M.A. from the Hebrew University of Jerusalem, School of Librarianship and Information, Israel. She is Head of the Librarianship \& Information Science Department, Oranim Academic College of Education, Tivon, Israel. She also teaches at the Haifa University, Librarianship and Information Studies. For over 20 years she supervised and developed school libraries at ORT Educational Network in Israel. 
Reproduced with permission of the copyright owner. Further reproduction prohibited without permission. 